Employee Stock Options: Much More Valuable Than You Thought

James Hodder and Jens Carsten Jackwerth 


\title{
Employee Stock Options: Much More Valuable Than You Thought
}

\author{
by \\ James E. Hodder \\ and \\ Jens Carsten Jackwerth
}

February 28, 2005

C: $\mid$ Dokumente und Einstellungen $\backslash$ Frau Fischer $\backslash$ Desktop $\backslash$ Version9.doc

James Hodder is from the University of Wisconsin-Madison, Finance Department, School of Business, 975 University Avenue, Madison, WI 53706, Tel: 608-262-8774, Fax: 608-265-4195, jhodder@bus.wisc.edu.

Jens Jackwerth is from the University of Konstanz, Department of Economics, PO Box D-134, 78457 Konstanz, Germany, Tel.: +49-(0)7531-88-2196, Fax: +49-(0)7531-88-3120, jens.jackwerth@uni-konstanz.de.

We would like to thank George Constantinides and Mark Rubinstein for helpful comments. 


\title{
Employee Stock Options: Much More Valuable Than You Thought
}

\begin{abstract}
Previous papers have argued that trading restrictions can result in a typical employee stock option having a subjective value (certainty equivalent value) that is substantially less than its Black-Scholes value. However, these analyses ignore the manager's ability to (at least partially) control the risk level within the firm. In this paper, we show how managerial control can lead to such options having much larger certainty equivalent values for employees who can exercise control. We also show that the potential for early exercise is substantially less valuable with managerial control.
\end{abstract}

The certainty equivalent value for a European option with managerial control can easily exceed the Black-Scholes value for a comparable option without control. However, it is questionable whether Black-Scholes is an appropriate benchmark for an option where the underlying process exhibits controlled volatility. We show how to obtain a risk-neutral valuation for such an option. That risk-neutral value can be substantially greater or less than the BlackScholes value. Furthermore, the option's certainty equivalent value can also be greater or less than its risk-neutral value. 


\section{Employee Stock Options: Much More Valuable Than You Thought}

It is widely recognized that restrictions on trading the underlying asset reduce the value of employee stock options from the perspective of the individual employee. Numerous papers have addressed the valuation of such options. ${ }^{1}$ A typical approach has been to assume a utility function for the (representative) individual employee and to calculate a subjective certainty equivalent value (CEV) for the option. Most papers have utilized power utility, which results in certainty equivalent values that depend importantly on the employee's relative risk aversion and the fraction of his wealth tied up in the firm's securities. When the option is treated as European, previous papers have found its subjective value to be much less than the Black Scholes price for an otherwise equivalent tradable option. With moderate risk aversion and a substantial portion of wealth (say 50\%) in the firm's securities, that subjective value can be less than half the BlackScholes price. ${ }^{2}$ Many employee stock options have American-style features and can be exercised early after a specified vesting period. This increases the subjective value somewhat; but with the same wealth and risk aversion parameters, that value would still be well below the Black-Scholes price of a tradable European option. ${ }^{3}$

One reason for interest in the subjective value of employee stock options has been the accounting debate about how they should be valued for reporting purposes. If an employee values an option at substantially less than what the firm uses to measure its cost, then that option becomes an expensive form of compensation. There has also been interest in measuring that subjective value's sensitivity to incremental stock price changes (analogous to delta) and using that result as an estimate of the option's incentive effect for the employee. There is also the issue that the option may not correctly align the employee's preferences with those of shareholders for example, see Lewellen (2003).

The usual argument for employee stock options and shares is that they provide an incentive for firm managers to act in the shareholders' interest. As a practical matter, managers do take sequences of actions over time to "control" the firm's profitability and risk. This

\footnotetext{
1 A partial listing of such papers includes Carpenter (1998), Detemple and Sundaresan (1999), Hall and Murphy (2002), Huddart (1994), Ingersoll (2004), Kulatilaka and Marcus (1994), plus Lambert, Larcker, and Verrecchia (1991).

2 For example, see Hall and Murphy (2002, Table 1) or Ingersoll (2004, Table 1).

3 Unlike tradable options, it may be optimal on a utility maximization basis to exercise an employee stock option prior to maturity even if the firm's stock does not pay dividends.
} 
dynamic aspect of managerial control has been missing from previous attempts to value employee stock options which assume a fixed as opposed to a dynamically optimal control. Below, we develop a model where a single individual (the manager) can dynamically control the stochastic process for the firm's value. He does this in a manner that maximizes his expected utility of terminal wealth, which depends in part on the payoff from his restricted stock and incentive option positions. Like most previous papers, we use power utility; although other utility functions would be possible with our approach.

The fundamental difference between our model and previous work is that the manager can now dynamically influence the firm's stock price. Previous papers have recognized this issue but have been unable to deal with it. For example, Huddart (1994, p. 211) explicitly states that his paper "assumes the parameters of the stock price process are stationary irrespective of employee actions." Carpenter (1998, p. 136) notes that the utility-maximizing model she uses "abstracts" from the complication that "the option holder has some control over the underlying stock price process." In contrast, allowing the manager to dynamically control the firm's value process has important implications not only for how the firm is managed but for how one thinks about pricing securities whose value depends on that controlled process.

As a starting point, think of the firm's value as being like a portfolio comprised of a position in a risky technology plus a position in a riskless investment. Assume that the manager can control the firm's value process by adjusting the portfolio weight of the risky technology. There is a strong analogy to the portfolio investment problem of Merton (1969) where an individual with power utility optimally invests a constant fraction of his wealth in the risky security. Indeed, under some simplified conditions, our manager would follow an analogous strategy. However, once we introduce influences on managerial behavior such as incentive options or the possibility of losing one's job, the manager's behavior varies dramatically from the simple Merton-style solution.

An issue is how much control a manager can exercise in practice. If the firm produces outputs or uses substantial amounts of inputs that have traded futures (or other financial contracts), its risk and expected return can be altered very quickly. There are numerous examples such as utilities hedging (or not) in electricity as well as natural gas markets, airlines with aviation fuel, oil producers as well as refiners, agricultural firms, mining companies, etc. Furthermore, any firm with substantial foreign exchange exposure can effectively have its stock price process altered in a matter of minutes. 
In this paper, we allow the manager to make weekly adjustments to the firm's value process but limit the extent of those adjustments - analogous to limits on portfolio leverage. Tighter limits proxy for a manager who has less ability to control firm risk and return. The manager's control of the value process results in a terminal distribution that is decidedly not lognormal. This should not be surprising since managerial control is intended to alter the outcome distribution. However, it is rather striking that managerial control in response to an incentive option and the threat of possible dismissal can result in a trimodal distribution. Typically, the manager's control ability allows him to dramatically increase the subjective value of his incentive option.

Once we have determined the manager's optimal control behavior, we can calculate the risk-neutral density of firm value and use this to obtain what FAS 123(R) calls "fair value" for his employee stock option. ${ }^{4}$ One can view the manager's control behavior as altering firm volatility. This suggests the possibility of estimating fair value using the Black-Scholes model with a forecast of average volatility. However, it turns out that things are not that simple; and such an approximation can contain substantial error.

Examining incentive options with possible early exercise, we find surprisingly low subjective early exercise premiums for managers with low to moderate levels of risk aversion. For these individuals, the probability of getting deep enough in-the-money to warrant early exercise is quite low. This occurs because the manager's control ability considerably enhances the value of keeping his option "alive" and hence reduces the early exercise premium. Conversely, reducing the manager's control ability increases the early exercise probability and hence the premium for an American-style option. If the manager has a relatively high degree of risk aversion, the difference between certainty equivalent values for American and European options is relatively large. Again, the reason has to do with control ability. With relatively high levels of risk aversion, our limits on the manager's control ability start to bind in areas of the state space that dramatically affect the early exercise premium.

In the next section, we describe the basic model and solution methodology for determining the manager's optimal control. Section II provides illustrative results for a base case set of parameter values. The optimal control used by the manager is displayed as a surface of

4 In the finance literature, the terms "objective value" and "market value" have also been used instead of fair value. Ingersoll (2004) reserves the term objective value for the risk-neutral valuation of a suboptimally exercised American-style employee stock option. 
risk-taking which depends on the current firm value and time until the incentive option matures. We also display an example of the induced trimodal distribution of firm values at the option's maturity date. In Section III, we calculate values for the manager's incentive option based on his expected utility maximizing control of the firm's value process. We explore how those values vary with his risk aversion and the degree to which his wealth is concentrated in firm stock. We also examine the implications of his control ability both for certainty equivalent values of European options and for the desirability of early exercise. Section IV discusses several issues surrounding the calculation of fair value. Concluding comments are provided in Section V.

\section{The Basic Model and Solution Methodology 5}

In modeling managerial control, we attempt to introduce considerable realism while still retaining tractability. We will first address the stochastic process for the firm's value. Next, we discuss the manager's compensation conditional on both his pay package and the possibility of dismissal at a lower boundary. Finally, we show how the manager optimally controls the firm value process to maximize his expected utility. Our approach utilizes a numerical procedure, with details on the implementation available in Appendix A.

\section{A. The Stochastic Process for Firm Value}

Assume the firm's operating assets are invested in a risky technology that over a time step $\Delta \mathrm{t}$ generates normally ${ }^{6}$ distributed $\log$ returns with mean $\mu \Delta t-\frac{1}{2} \sigma^{2} \Delta t$ and volatility $\sigma \sqrt{\Delta t}$. Also assume there exist forward contracts which can be used to hedge (perhaps partially) the firm's risk from this technology. Let $X$ denote the value of the firm's assets and $\kappa$ the fraction of those assets which are unhedged. That is, $(1-\kappa) \mathrm{X}$ represents hedged assets, which are assummed to earn a constant riskless interest rate $r$. We have a single manager controlling

\footnotetext{
5 Parts of the following discussion are also covered in Hodder and Jackwerth (2004) where a related model is used to examine the impact of incentive contracts on the behavior of a hedge fund manager. Compare also Judd (1998, ch. 12) for further details on numerical dynamic programming.

${ }^{6}$ Our approach is not restricted to the normal distribution, and we can add undiversifiable risk or jumps to generate more complicated discrete distributions. The qualitative pattern of optimal risk taking remains the same; however, the manager acts more prudently if the new distribution increases the chance of dismissal.
} 
$\kappa$, which is short for $\kappa(\mathrm{X}, \mathrm{t})$. Typically, some portion of the firm's operations cannot be hedged. We model this situation by having a positive lower bound on $\kappa$. We also allow for the possibility that the manager can increase firm risk by choosing $\kappa$ values greater than one. ${ }^{7}$ To model differing degrees of managerial flexibility, we will utilize differing upper and lower bounds on $\kappa$.

For a given control value $\kappa$, the log returns on the firm value $X$ are normally distributed over each discrete time step of length $\Delta \mathrm{t}$ with mean $\mu_{\kappa, \Delta t}=\left[\kappa \mu+(1-\kappa) r-\frac{1}{2} \kappa^{2} \sigma^{2}\right] \Delta t \quad$ and volatility $\sigma_{\kappa, \Delta t}=\kappa \sigma \sqrt{\Delta t}$. The following analysis uses weekly time steps; however, we have also conducted runs using time steps equal to one trading day with no change in our qualitative results.

We discretize the log firm values onto a grid structure (more details are provided in Appendix A). That grid has equal time increments as well as equal steps in $\log X .{ }^{8}$ From each grid point, we allow a multinomial forward move to a relatively large number of subsequent grid points (e.g. 41) at the next time step. We structure potential forward moves to land on grid points and calculate the associated probabilities by using the discrete normal distribution with a specified value for the control parameter kappa.

\section{B. The Manager's Compensation Structure}

We assume the manager has outside wealth that is invested in the riskless asset. At the horizon time $\mathrm{T}$, that wealth has a value denoted by the symbol a. Some of that wealth could also be interpreted as a fixed salary component of the manager's compensation. He also owns a fraction (b) of the firm's shares, which are restricted and cannot be sold prior to T. Finally, the manager has employee stock options for a further fraction (c) of the firm's shares. These options have a maturity of $\mathrm{T}$ and are issued at-the-money.

We allow the firm to dismiss the manager for poor performance. This is modeled by having a lower boundary on $\mathrm{X}$, where the manager is fired. We denote that boundary by $\Phi$, and set it at $50 \%$ of the initial firm value $\mathrm{X}_{0}$. There are a variety of assumptions one could make

\footnotetext{
${ }^{7}$ An alternative way to think about this model structure is to interpret $\kappa$ values greater than one as representing a levered firm, with the manager able to dynamically adjust the firm's capital structure.

${ }^{8}$ To economize on notation, we assume the firm value $\mathrm{X}$ and the time $\mathrm{t}$ are always multiples of $\Delta(\log \mathrm{X})$ and $\Delta \mathrm{t}$ without the use of indices.
} 
about the wealth impacts of being fired. Many CEOs and other high-level executives have employment contracts that specify a severance payment in the event of termination. If that payment is large, it is often described as a "Golden Parachute." On the other hand, the manager might lose any non-vested shares. Also, being fired might negatively impact the manager's human capital.

The aggregate effect of these various possibilities represents a net penalty for hitting the lower boundary. Increasing that penalty makes the manager more cautious near the lower boundary; however, this has only a minor impact on his subjective valuation of an at-the-money option. Hence, we use a rather simple structure with no explicit penalty for hitting the boundary. However, the manager's option position (which is out-of-the-money) is cancelled. His restricted shares are also immediately liquidated at the prevailing price; but he does not receive the proceeds until time $T$. This represents a modest penalty in the sense of receiving no interest on those funds during that period. However, losing the ability to manage the firm and hence influence the value of his shares and options represents an even larger implicit penalty. In summary, if the lower boundary is hit at time $\tau$, the manager's wealth at $\mathrm{T}$ will be:

$$
W_{T}=a+b X_{\tau}
$$

On the other hand, when the manager is not dismissed, his wealth at $\mathrm{T}$ equals:

$$
W_{T}=a+b X_{T}+c\left(X_{T}-X_{0}\right)^{+}
$$

\section{The Optimization of Expected Utility}

We assume the manager seeks to maximize expected utility of terminal wealth $\mathrm{W}_{\mathrm{T}}$ and has a utility function that exhibits constant relative risk aversion $\gamma$ (an assumption that can readily be relaxed):

$$
U=\frac{W_{T}^{1-\gamma}}{1-\gamma}
$$


For each terminal firm value, we calculate the manager's wealth and the associated utility. We then step backwards in time to T- $\Delta \mathrm{t}$. At each possible firm value within that time step, we calculate the expected utilities for all control values $(\kappa)$ in a discrete choice set. For our standard case, $\kappa$ (which measures the manager's risk taking) can lie between 0.7 and 1.5 at steps of 0.1 . We choose the highest of those expected utilities as the optimal indirect utility for that firm value and denote its value as $\mathrm{J}_{\mathrm{X}, \mathrm{T}-\Delta \mathrm{t}}$. We record the optimal indirect utilities and the associated optimal risk taking for each firm value within that time step and then loop backward in time, repeating this process through all time steps. ${ }^{9}$ This generates the indirect utility surface and optimal risk-taking values for our entire grid. Formally:

$J_{X, T}=U_{X, T} ; \quad J_{X, t}=\max _{\kappa} E_{\kappa}\left[J_{X, t+\Delta t}\right]$

where $\mathrm{t}$ takes the values $T-\Delta t, \ldots, 2 \Delta t, \Delta t, 0$ one after another.

\section{Some Illustrative Results}

As an illustration, we calculate the manager's optimal control behavior using the set of parameters in Table 1.

Table 1

Standard Parameters

$\begin{array}{llllll}\text { Time to maturity } & \mathrm{T} & 1 & \text { Interest rate } & \mathrm{r} & 0.02 \\ \text { Log value steps below/above } \mathrm{X}_{0} & & 40 / 80 & \text { Initial firm value } & \mathrm{X}_{0} & 1.00 \\ \text { Risk aversion coefficient } & \gamma & 2 & \text { Mean } & \mu & 0.092 \\ \text { Number of time steps } & \mathrm{n} & 52 & \text { Volatility } & \sigma & 0.30 \\ \text { Manager's outside wealth } & \mathrm{a} & 0.0050 & \text { Min control value } & \underline{\kappa} & 0.70 \\ \text { Manager's shares } & \mathrm{b} & 0.0050 & \text { Max control value } & \bar{\kappa} & 1.50 \\ \text { Manager's options } & \mathrm{c} & 0.0040 & \text { Exit boundary } & \Phi & 0.50 \\ \text { Future nodes for the Normal approx. } & & 1+2 \times 20=41 & & & \\ \text { Log X step } & & (\log (1 / 0.5)) / 40 \approx 0.01733 & & \end{array}$

${ }^{9}$ The treatment of boundary layers is described in Appendix A. 
The horizon is one year with weekly adjustments of risk taking. The starting firm value of 1 equals the strike price for the manager's incentive options. The risky technology has a mean return of $9.2 \%$ and a volatility of $30 \%$. The riskless asset yields $2 \%$. This combination of annual mean returns and volatility implies a Sharpe Ratio of 0.24 . There are a total of 120 $\log$ steps for the firm value between the lower and upper boundaries with the initial firm value $\mathrm{X}_{0}$ being 40 log steps above the lower boundary. The risk aversion coefficient of the manager's power utility is $\gamma=2$. For our standard parameters, we use bounds on risk taking of 0.7 and 1.5. Compared with an unhedged position $(\kappa=1)$, our standard parameter structure allows the manager to reduce but not eliminate the firm's risk. He can also increase that risk but in a limited manner.

Before examining the manager's behavior with our full set of standard parameters, it is useful to build intuition by looking at a situation with relaxed kappa constraints. We do this in Figure 1, where we allow kappa to be chosen as low as 0 (using steps of 0.01). We maintain the upper bound on risk taking at 1.5; however, it is quite clear in Figure 1 where relaxing that upper bound would cause the manager to choose higher kappa values. The other parameters are the same as in Table 1. The optimal risk taking of a manager in Figure 1 exhibits essentially four different areas of economic behavior.

"Suicide Ridge" at the far left front of Figure 1 is not surprising. Here the manager is in a situation well before $\mathrm{T}$ that could be described as "heads: I win, tails: I don't lose very much." The winning is associated with a large up-move which increases the value of both his shares and the possibility of his employee stock option finishing in the money. The losing is associated with being dismissed right away, which is only slightly worse then sitting just above the dismissal boundary with essentially no chance of having his option finish in-the-money. Although he is risk averse, the manager typically desires having a substantial portion of his total wealth invested in risky assets. Since his outside wealth is invested in the riskless asset, this also motivates him toward having a high kappa near the lower boundary for the relatively modest wealth he has invested there in firm shares. The combination of these two forces causes him to gamble with a very large kappa near the lower boundary. Here we have limited the kappa values to a maximum of 1.5 , but he would utilize a much higher value if that were allowed. Nevertheless, even with the limited kappa range, his gambling behavior is pronounced. 
Figure 1. Optimal Risky Investment Proportion (к) with minimal allowed kappa =0

We depict the optimal kappa surface using the standard parameters from Table 1 except that the manager is allowed to choose kappa values as low as zero. To increase smoothness, the kappa levels in this graph are 0.01 apart and can range from 0 to 1.5 .

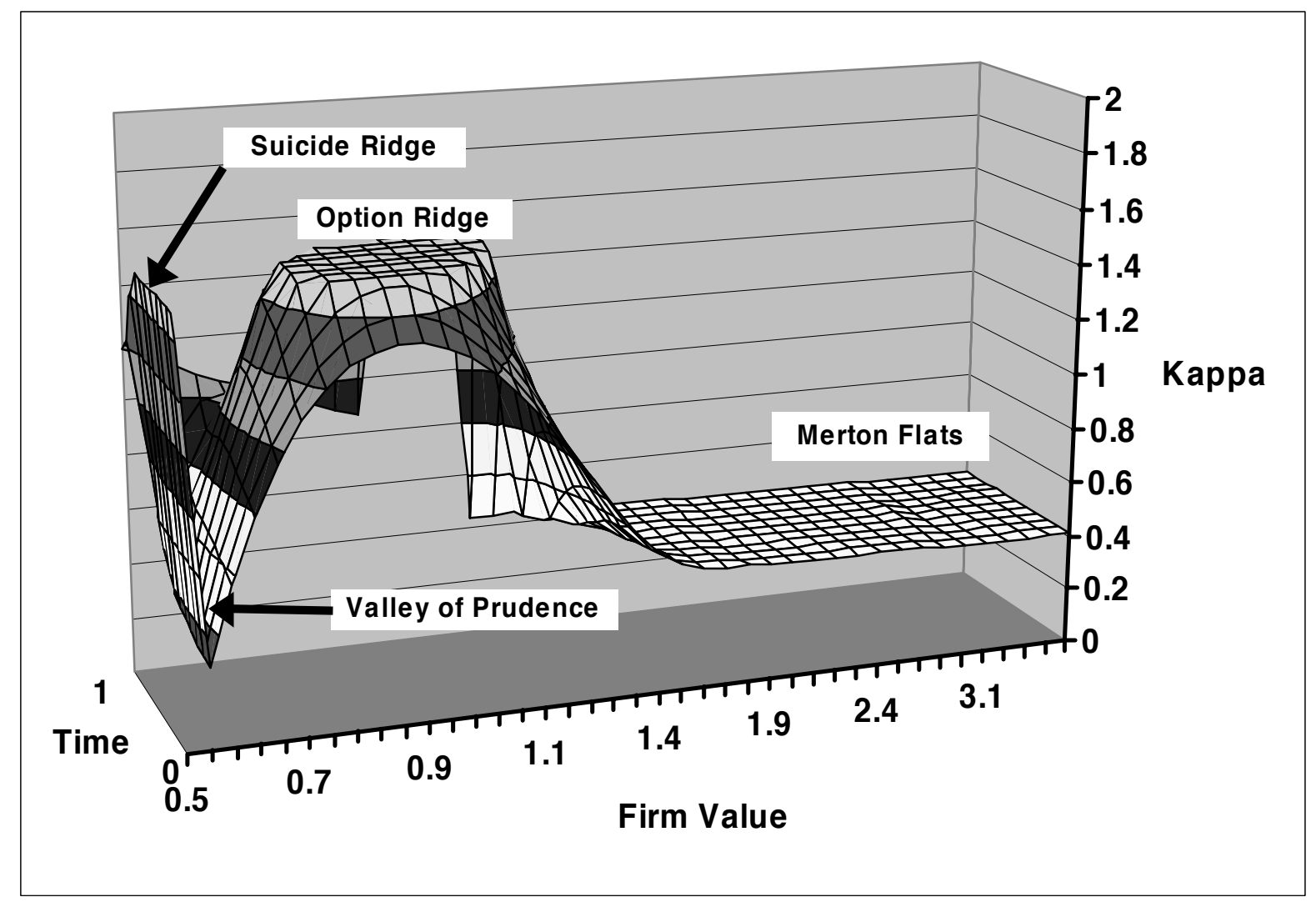

The "Valley of Prudence" in Figure 1 can be interpreted as a region where the manager chooses a very low kappa in order to dramatically reduce the chance of hitting the lower boundary at an early date. Hitting that boundary early incurs an implicit cost since the manager is no longer able to potentially improve his compensation by continuing to manage the firm. Approaching the terminal date, the remaining potential for gaining from continued management becomes progressively smaller.

Toward the center of Figure 1 there is a region of high kappa values, which we labeled "Option Ridge". This region is centered just below the option strike price of 1. Again, the manager dramatically increases the firm's riskiness, but now the motivation is to increase the 
chance of finishing with his option substantially in-the-money. Again, he would like to increase kappa even further but is limited by the maximum of 1.5 . That restriction leads to the flat top for Option Ridge in this figure.

Somewhat above the strike price, Option Ridge declines toward what we have called "Merton Flats." The allusion here is to a result from Merton (1969). In that paper, an individual (analogous to our manager) dynamically chooses the optimal allocation of available funds between risky shares and the riskless asset. In the case where there is no intermediate consumption (between 0 and $\mathrm{T}$ ), he chooses that investment strategy to maximize his expected utility of terminal wealth $\left(\mathrm{W}_{\mathrm{T}}\right)$. Merton's analysis is in continuous time (as opposed to our discrete-time framework); however, that description approximates the situation of our manager for high $\mathrm{X}$ values. There, the employee stock option is sufficiently deep in-the-money that it starts to behave almost like a share position. Also, the manager is far enough from the lower boundary that the possibility of dismissal plays virtually no role in his optimal decision. Moreover, his outside wealth has a relatively minor effect on the optimal kappa choice in that region.

In Merton's framework, the optimal proportion allocated to the risky investment would be constant, and using parameters from Table 1 implies:

$$
\kappa=\frac{(\mu-\mathrm{r})}{\gamma \sigma^{2}}=0.4
$$

The optimal kappa surface exhibits a slight downward slope in the Merton Flats area as optimal kappas decline toward 0.4 in the limit.

In Figure 2, we increase the minimum allowed kappa to 0.7 (the range of permissible kappas is now 0.7 to 1.5 ). That lower limit could be either due to fixed assets in place which cannot be completely hedged or to the manager having less ability to alter the firm's positions. ${ }^{10}$ As a result, we find that the Valley of Prudence is now limited to a depth of 0.7 and that the Merton Flats region toward the right of Figure 2 is also forced up to a level of 0.7 .

${ }^{10}$ In the limit, a manager with no control ability would be unable to adjust kappa. 
Figure 2. Optimal Risky Investment Proportion (к) with minimum allowed kappa $=0.7$

We depict the optimal kappa surface using the standard parameters from Table 1. The kappa levels in this graph are 0.01 apart (to increase smoothness) and can range from 0.7 to 1.5.

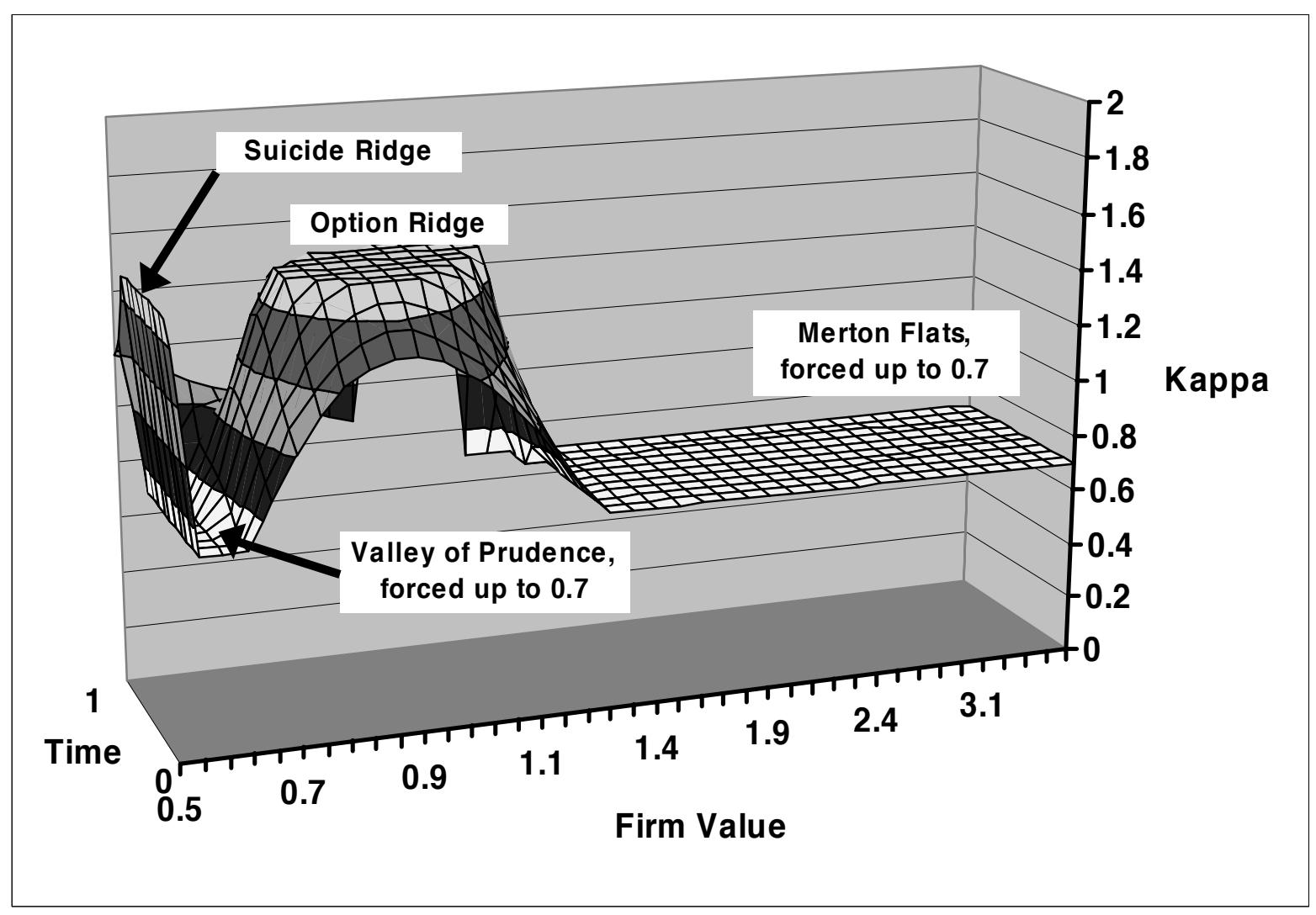

In Figure 3, we depict the return distribution at time $\mathrm{T}$ resulting from the manager optimally adjusting the risk level during the period from 0 to $T$ (as shown in Figure 2). For comparison in Figure 3, we also plot a lognormal distribution using $\mu=0.092$ and $\sigma=0.3$ (the same volatility and drift parameters as our risky technology). There is a pronounced trimodality in the managed return distribution, with the bottom spike corresponding to the probability of hitting the dismissal boundary of 0.5 on or before time $T$. The trimodality is driven in part by the manager's desire to move his employee stock option into the money. The resulting high kappa values on Option Ridge lead to probability mass being shifted either upwards or downwards into regions where the risk-taking is lower. The high kappa values along Suicide 
Ridge lead to probability mass being shifted either upward toward the middle mode of the distribution or downward into the "dismissal" spike.

Figure 3. Terminal Value Distribution of the Optimally Managed Firm

We depict the terminal value distribution of the firm, when the manager optimally manages the risk taking to maximize his expected utility. The spike at and slightly below the lower boundary of 0.5 represents situations where the manager hits the boundary and is dismissed. Presumably, the firm continues to operate with a new manager from that hitting time until time $\mathrm{T}$; however, we have not modeled that portion of the value process and simply report the value at the hitting time. The manager receives the standard compensation contract as specified in Table 1 with the minimum allowed kappa at 0.7 . For comparison, we include a graph of the corresponding lognormal return distribution using $\sigma=0.3$ and $\mu=0.092$.

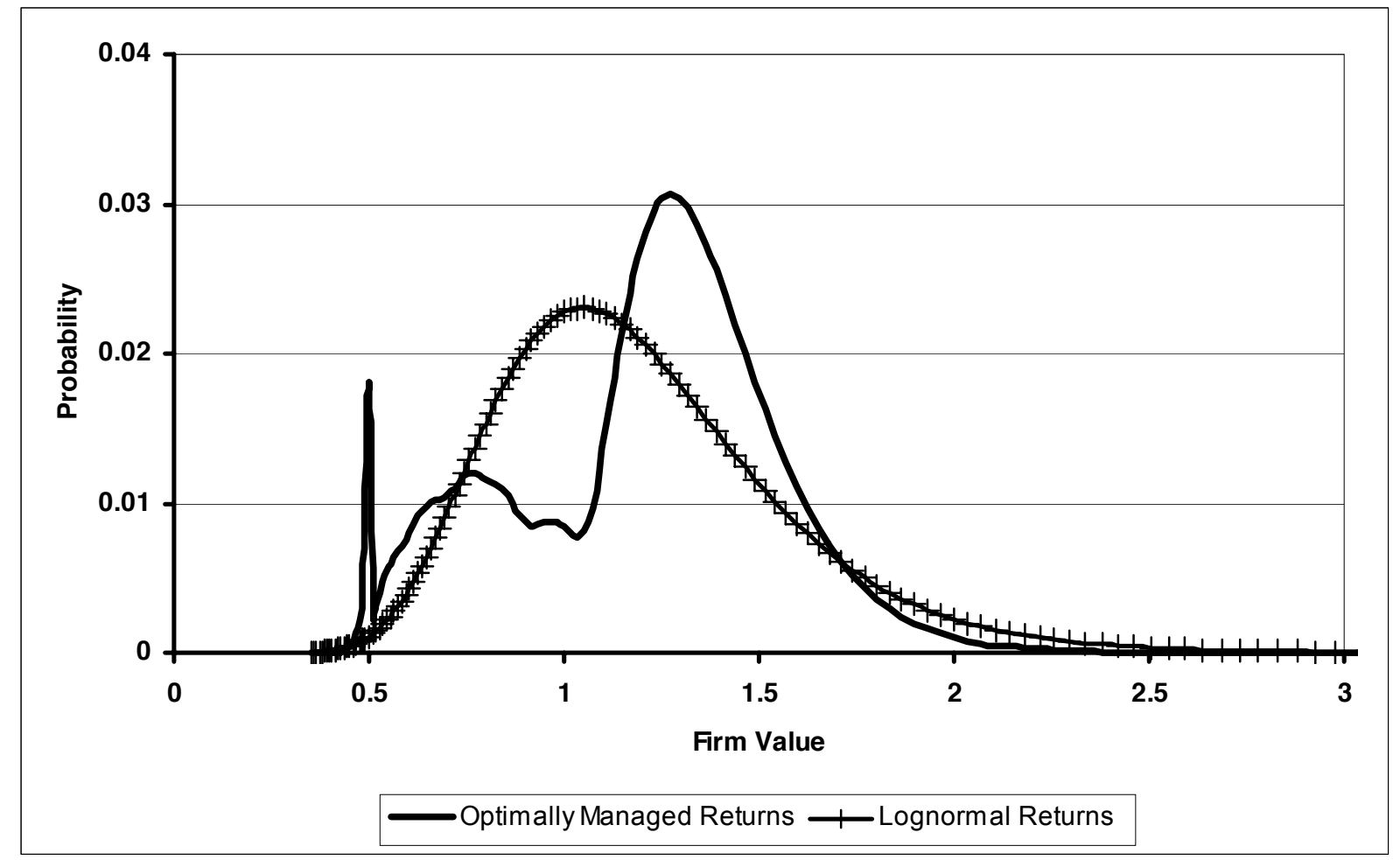

\section{Subjective Valuation and Early Exercise with Managerial Control}

We are now ready to embark on valuing the employee stock option position of the manager. We compute the certainly equivalent values by working out the marginal value of one small unit of 
option to the manager, given the standard parameters from Table $1 .{ }^{11}$ We collect these values for varying upper limits on risk taking in Table 2. The employee stock option in the standard case (kappa can range from 0.7 to 1.5 ) is worth 0.1253 . Further limiting the manager's ability to control firm risk and return via adjusting kappa will reduce the certainty equivalent value of his option. For example, constraining the maximum kappa at 1.0 (with the minimum kappa still at 0.7) corresponds to a situation where he can partially hedge the firm's risk but cannot increase it above the unhedged level $(\kappa=1.0)$. Under these conditions, his certainty equivalent value falls to 0.1048 - a reduction of over $16 \%$. Allowing the manager to have greater flexibility by relaxing the upper limit so that kappa can be above 1.5 allows him to increase his certainty equivalent value. However, using the other standard parameters from Table 1, there is essentially no further gain in the certainty equivalent value (to four decimal places) from allowing kappa to exceed 5. Later we will consider some situations where the manager is stripped of all control. This corresponds to his having to maintain $\kappa=1.0$, with neither an ability to hedge nor to increase the firm's risk. For a fixed $\kappa=1.0$, his certainty equivalent value drops to 0.0990 (not shown in Table 2).

The bottom row of Table 2 displays option values allowing for early exercise (computational details are in Appendix B). The values displayed in Table 2 are based on exercising for stock, which continues to be held. Exercising for cash yields similar values, given our other parameters. Interestingly, the possibility of early exercise has only a minor effect on the option values in Table 2. The manager's ability to adjust kappa not only enhances the certainty equivalent value of his incentive option but also reduces the attractiveness of early exercise, since early exercise eliminates his continued control and the possibility of utility improving future risk taking.

11 To compute the certainty equivalents, we calculate the lump-sum amount of money at time 0 which, invested at the risk free rate until time $\mathrm{T}$, would yield the same indirect utility as having the contract specified in Table I. That calculation considers outside wealth as well as restricted shares and the option. We next compute the numerical sensitivity of that lump-sum amount for an increase in the option position of $1 \%$. This proxies for the marginal value of adding a small option position, expressed in certain wealth at time 0 . For the parameters of Table 1 , this marginal value is very close to the average certainty equivalent value. The marginal and average values differ more when the manager has very little wealth other than the option. 
Table 2

\section{Certainty Equivalents for Varying Caps on Risk Taking}

We report the certainty equivalent value (CEV) of a marginal employee stock option struck atthe-money. In this table, the manager's maximum kappa level is allowed to go up to 10. Other parameter values are from Table 1. Due to the high kappa values examined here, we use 201 probability states in order to allow for improved moment matching of the discrete normal distribution.

\section{Option Values}

European CEV

American CEV

\section{Maximum Allowed Kappa}

$\begin{array}{lllll}1 & 1.5 & 2 & 5 & 10\end{array}$

$\begin{array}{lllll}0.1048 & 0.1253 & 0.1328 & 0.1399 & 0.1399\end{array}$

$\begin{array}{lllll}0.1049 & 0.1254 & 0.1330 & 0.1400 & 0.1400\end{array}$

Despite the small valuation effect in Table 2, early exercise can occur over a rather wide range of firm values. This is illustrated in Figure 4 using the same parameters that generated the values in Table 2 and focusing on a maximum allowed kappa of 1.5 .

The seeming disparity between Table 2 and Figure 4 is explained by the rather small probability of starting at-the-money and winding up in the early exercise region within one year. Longer maturities and/or higher volatilities can substantially increase that probability. Also, restricting the manager's control by fixing $\kappa=1$ leads to much more wide-spread early exercise behavior. 


\section{Figure 4. Optimal Early Exercise of the Employee Stock Option}

We depict the optimal early exercise decision of a manager who receives the standard compensation contract as specified in Table 1. The initial firm value is 1. The kappa is restricted to be between 0.7 and 1.5 . To better illustrate the early exercise boundary, we utilize 2500 time steps in the underlying calculations.

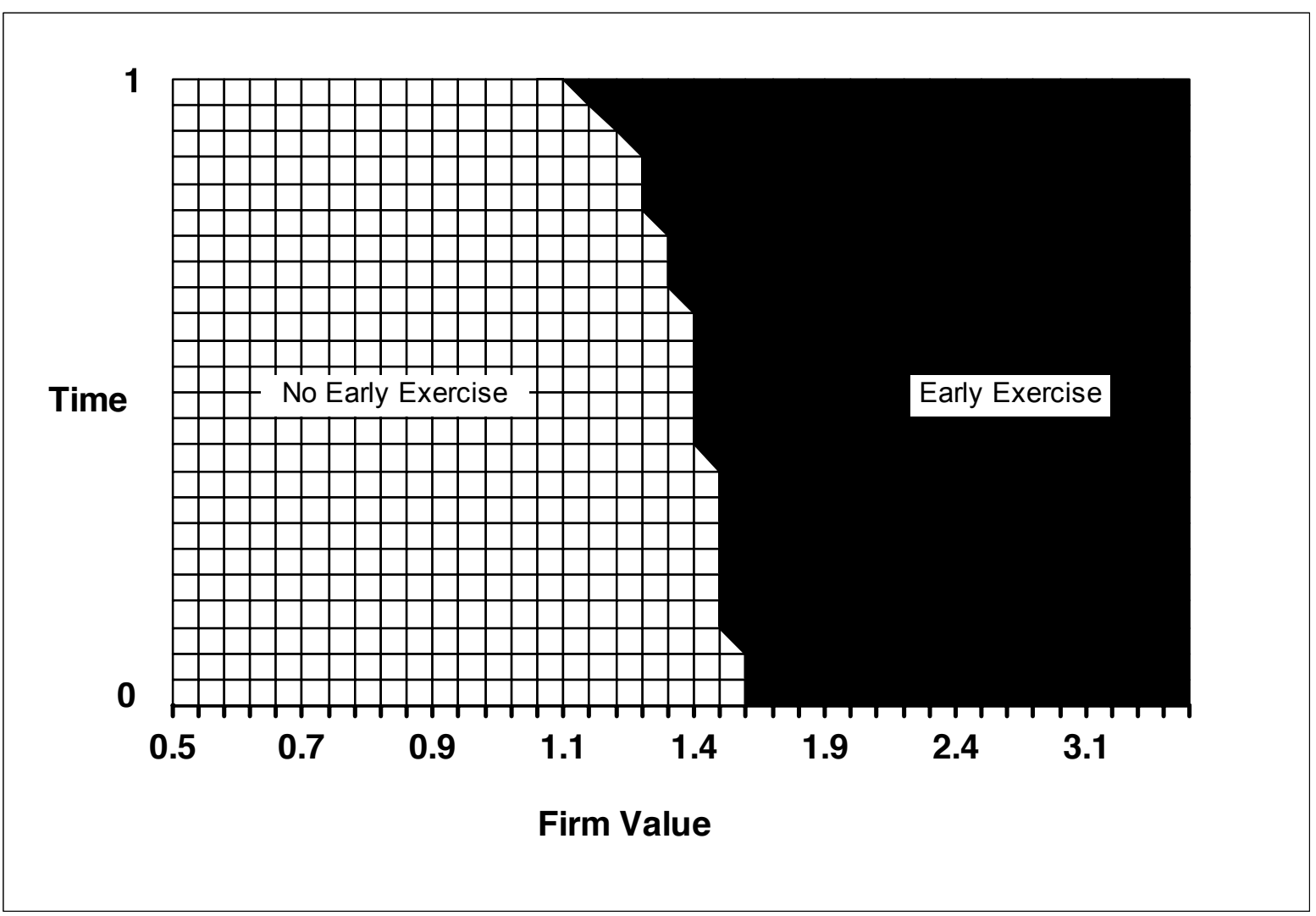


Table 3

\section{Certainty Equivalents for Differing Risk Aversion and Initial Wealth Structures with 1-Year Maturity Options}

We report the certainty equivalent value of a (marginal) employee stock option struck at-themoney for various levels of Relative Risk Aversion (gamma) and initial wealth distributions $\left[\mathrm{b} /\left(\mathrm{a}^{\prime}+\mathrm{b}\right)\right]$. Other parameters are as specified in Table 1 . Values in the right half of the table are for American options.

Wealth in
Stock $(\%)$

20
50
80

Relative Risk Aversion

$0.5 \quad 2 \quad 4$

European Options

1 Year CEV

$0.2238 \quad 0.1584 \quad 0.1107$

$0.2102 \quad 0.1259 \quad 0.0647$

$\begin{array}{lll}0.1988 & 0.0863 & 0.0425\end{array}$
Relative Risk Aversion

$0.5 \quad 2 \quad 4$

American Options

1 Year CEV

$0.2238 \quad 0.1584 \quad 0.1152$

$0.2102 \quad 0.1260 \quad 0.0711$

$0.1988 \quad 0.0882 \quad 0.0523$

In Table 3, we explore the effect of altering the manager's risk aversion as well as the distribution of his initial wealth. First, let us define his initial outside wealth $a^{\prime}$ as the value of his terminal wealth a, discounted at the risk free rate. Then, we can define the wealth distribution as the initial value of the manager's shares $\left(\mathrm{bX}_{0}\right)$ divided by his initial outside wealth plus shares $\left(a^{\prime}+b X_{0}\right)$. Since $X_{0}=1$, this ratio reduces to $b /\left(a^{\prime}+b\right)$. Increasing this ratio decreases the certainty equivalent value of his employee stock option. The effect is more pronounced for higher levels of relative risk aversion.

Increasing his relative risk aversion dramatically reduces the certainty equivalent value of his option. It also increases the probability of early exercise -- compare the American option values when relative risk aversion is 4 with those for the European option. The difference is due to the increased probability of early exercise as compared with the situation when his relative risk aversion is lower. Recall that with our standard parameters (including $50 \%$ of initial wealth in the firm's stock and $\gamma=2$ ) there was a large region of early exercise illustrated in Figure 4 but a relatively small probability of reaching that region from the initial starting point. Increasing the manager's risk aversion greatly increases the size of that region and thus the probability of reaching it. Having more initial wealth in the firm's stock amplifies this effect. 


\section{Table 4}

\section{Certainty Equivalents for Differing Risk Aversion and Initial Wealth Structures with 10-Year Maturity Options}

We report the certainty equivalent value of a (marginal) employee stock option struck at-themoney for various levels of Relative Risk Aversion (gamma) and initial wealth distributions $\left[\mathrm{b} /\left(\mathrm{a}^{\prime}+\mathrm{b}\right)\right]$. A 10 year maturity with 520 time steps is used, while other parameters are as specified in Table 1. Values in the right half of the table are for American options. In the lower panel we provide the ratios of the 10 year certainty equivalent values to their 1 year counterparts.

Wealth in
Stock $(\%)$

20
50
80

20
50
80

\section{Relative Risk Aversion}

$0.5 \quad 2 \quad 4$

European Options

10 Year CEV

$\begin{array}{lll}1.0009 & 0.3968 & 0.1757 \\ 0.9178 & 0.2887 & 0.0756 \\ 0.8527 & 0.2009 & 0.0288\end{array}$

10 Year CEV/1 Year CEV

$\begin{array}{lll}4.47 & 2.51 & 1.59 \\ 4.37 & 2.29 & 1.17 \\ 4.29 & 2.33 & 0.68\end{array}$

Relative Risk Aversion

$\begin{array}{lll}0.5 & 2\end{array}$

American Options

10 Year CEV

$\begin{array}{lll}1.0090 & 0.3970 & 0.2051\end{array}$

$\begin{array}{lll}0.9178 & 0.2942 & 0.1147\end{array}$

$\begin{array}{lll}0.8527 & 0.2153 & 0.0707\end{array}$

10 Year CEV/1 Year CEV

$\begin{array}{lll}4.51 & 2.51 & 1.78 \\ 4.37 & 2.33 & 1.61 \\ 4.29 & 2.44 & 1.35\end{array}$

As seen in Table 4, a 10-year horizon results in substantial increases for most option values. In the lower portion of the table, we scale the 10-year certainty equivalent values by the corresponding value for an otherwise identical 1-year option. It shouldn't be surprising that most of these ratios are substantially above 1 . After all, we have both a longer maturity option and a situation where the manager can exercise control over that longer time period. What is perhaps surprising is the strong role of risk aversion in determining those ratios and that one ratio is below 1. This is caused primarily by restricting the minimum kappa to be at least 0.7 . Recall that with our standard parameters (including $\gamma=2$ ), the unrestricted location of Merton Flats is at 0.4.

Thus, our minimal kappa constraint is forcing a moderately risk averse manager to deviate from his optimal kappa in both the Valley of Prudence and in Merton Flats (see Figure 2). This dampens the benefits of a longer maturity. For a manager with high risk aversion $(\gamma=4)$, the constraint is even more restrictive; and over a period of 10 years, this has a major negative impact on his subjective option valuation. Again, more initial wealth in the stock amplifies this effect. The manager is being forced to follow what he considers to be seriously sub-optimal behavior 
regarding both his stock and option positions. Indeed, relaxing the lower constraint on kappa results in ratios for a highly risk-averse manager $(\gamma=4)$ that are similar to those for a manager with low risk aversion $(\gamma=0.5)$.

Note that for low and moderate risk aversion levels in Table 4, the American certainty equivalent value remains close to its European counterpart. In other words, the early exercise premium for these options remains small, despite the 10-year maturity. With greater risk aversion $(\gamma=4)$, this is no longer the case. Furthermore, larger restricted stock positions substantially increase the more risk-averse manager's willingness to exercise early. Again, this result is being driven by constraining that manager to have a minimum kappa at 0.7 which is considerable different from what he would prefer for a substantially in-the-money option located in Merton Flats. We explore these issues further by considering an option which was issued atthe-money with a 10-year maturity five years ago. That option now has 5 years remaining to maturity and may be substantially in-the-money. Moreover, any vesting period (typically 4 years or less) has presumably passed; and an American-style option could be exercised immediately.

In Table 5, we examine the early exercise premium with both moderate risk aversion $(\gamma=2)$ and relatively high risk aversion $(\gamma=4)$. Throughout, we have $50 \%$ of the manager's wealth in the firm shares. For the column labeled Managerial Control, the kappa value can be optimally adjusted between 0.7 and 1.5. Consider first, the upper panel with $\gamma=2$. Even for a relatively deep-in-the-money option with a firm value of 2 , the difference between the American and European certainty equivalent values is only about $2 \%$. Now consider the same situation except that the manager is precluded from exercising any control - kappa is fixed at 1.0. All certainty equivalent values are lower, since the manager can no longer benefit from exercising control. Note, however, that the impact on the European CEV is substantially more than on the American counterpart. Early exercise becomes much more valuable. Indeed, with a firm value of 2, the American and European CEVs exhibit a difference of almost 24\%. In other words, reduced managerial control can dramatically increase the premium for an American option (and the probability of early exercise). 


\section{Table 5}

\section{Certainty Equivalents with 5 Years to Maturity with and without Managerial Control}

We report the certainty equivalent values of a (marginal) employee stock option struck at $\mathrm{X}_{0}=1$ with 5 years remaining to maturity (and 260 time steps) but which are now at varying levels of moneyness. Values in the right half of the table are for options where kappa is fixed at 1.0 and not subject to managerial control. The upper portion half of the table uses relative risk aversion (gamma) of 2 while the lower half uses relative risk aversion of 4 . Other parameters are as specified in Table 1.

Firm Value

\begin{tabular}{|c|c|c|}
\hline & $\begin{array}{c}\text { European } \\
\text { C E V }\end{array}$ & $\begin{array}{c}\text { American } \\
\text { CEV }\end{array}$ \\
\hline & \multicolumn{2}{|c|}{$\operatorname{gamma}=2$} \\
\hline 0.695 & 0.0726 & 0.0730 \\
\hline 1 & 0.2205 & 0.2228 \\
\hline \multirow[t]{2}{*}{2} & 1.0142 & 1.0435 \\
\hline & \multicolumn{2}{|c|}{ g a m $\mathrm{ma}=4$} \\
\hline 0.695 & 0.0211 & 0.0253 \\
\hline 1 & 0.0821 & 0.1086 \\
\hline 2 & 0.5258 & 0.8628 \\
\hline
\end{tabular}

\section{No M anagerial Control}
European American
CEV C E V
g a m m a $=2$
$0.0566 \quad 0.0628$
$0.1709 \quad 0.1947$
$0.7515 \quad 0.9418$

g a m m a $=4$

$\begin{array}{ll}0.0138 & 0.0234 \\ 0.0454 & 0.0900 \\ 0.2326 & 0.6669\end{array}$

Now consider the lower panel, where the manager is considerably more risk averse $(\gamma=$ 4). Recall in Table 4 that with relatively high risk aversion, the early exercise premium became substantial - even with only $50 \%$ of the manager's wealth in restricted shares. We see the same situation in Table 5. For a firm value of 2 and $\gamma=4$, the premium for an American option is now 64\%. The same situation without managerial control results in an American option being worth almost 3 times its European counterpart. Once again, it is not risk aversion per se that causes these large early exercise premiums. Rather, the lower bound on kappa is forcing the more risk averse manager to deviate markedly from his desired behavior which dramatically enhances the attractiveness for him of early exercise. 


\section{Fair Value for an Employee Stock Option with Managerial Control}

To provide a comparison with previous papers, we report in Table 6 the European certainty equivalent values for the one-year option from Table 3 scaled by the Black-Scholes price calculated using parameter values from Table $1 .^{12}$ In particular, an at-the-money call option using an initial stock price of 1 , one year to expiration, a $2 \%$ riskfree rate, and $30 \%$ volatility has a Black-Scholes price of 0.1282 .

\section{Table 6}

\section{Certainty Equivalents for Differing Risk Aversion and Initial Wealth Structures with 1-Year Maturity Options}

We report the certainty equivalent value of a (marginal) employee stock option struck at-themoney for various levels of Relative Risk Aversion (gamma) and initial wealth distributions $\left[b /\left(a^{\prime}+b\right)\right]$. Other parameters are as specified in Table 1 . The Black-Scholes value of this option is 0.1282 .

\begin{tabular}{|c|c|c|c|}
\hline \multirow{2}{*}{$\begin{array}{l}\text { Wealth in } \\
\text { Stock }(\%)\end{array}$} & \multicolumn{3}{|c|}{ Relative Risk Aversion } \\
\hline & 0.5 & 2 & 4 \\
\hline & \multicolumn{3}{|c|}{$\begin{array}{c}\text { European Options } \\
1 \text { Year CEV }\end{array}$} \\
\hline 20 & 0.2238 & 0.1584 & 0.1107 \\
\hline 50 & 0.2102 & 0.1259 & 0.0647 \\
\hline \multirow[t]{2}{*}{80} & 0.1988 & 0.0863 & 0.0425 \\
\hline & \multicolumn{3}{|c|}{1 Year CEV/BS Price } \\
\hline 20 & 1.75 & 1.24 & 0.86 \\
\hline 50 & 1.64 & 0.98 & 0.50 \\
\hline 80 & 1.55 & 0.67 & 0.33 \\
\hline
\end{tabular}

It's clear from the results in Table 6, that managerial control can result in certainty equivalent values which exceed the Black-Scholes price by substantial margins. However, there

\footnotetext{
12 In previous papers, Black-Scholes prices have presumably been used for comparison because that model is widely known and the prices are easily calculated. It also is consistent with a discrete-time economy and incomplete markets when the manager has power utility if risk taking is held constant --see Rubinstein (1976).
} 
is an issue as to whether that Black-Scholes price represents an appropriate yardstick for measuring the value of an option when the manager can exercise control over the firm's value process. One way to think about the situation is that by controlling kappa, the manager controls volatility. Hence, the constant volatility assumption in Black-Scholes is inappropriate.

The Financial Accounting Standards Board (FASB) has recently specified that firms should expense newly granted employee stock options based on their fair value. When possible, fair value is to be determined from the market price of the same or similar option. Absent the availability of such a market price, fair value is to be estimated using an option pricing model. If volatility were held constant, the Black-Scholes price would be a good starting point for a European option. In our situation, there is clearly a problem with that approach because of the expectation of non-constant volatility resulting from managerial control.

One might consider estimating an expected average volatility over the option's life and using that average as the volatility parameter in a Black-Scholes calculation. There would clearly be some problems with estimating an expected average volatility. An estimate based on historical volatility would be assuming that history was a good representation of the future in an expectation sense. If there had been a change either in managers or the incentive aspects of the manager's compensation contract, that assumption would be highly questionable. Even if no such changes had occurred, the historical volatility pattern over say the last year is analogous to one path through the state space grid for the next year. This does not seem like an estimate in which one should put much faith.

An alternative thought would be to back out the implied volatility from the market price of a traded option. One issue would be maturity. Employee stock options frequently have tenyear maturities, while traded options with maturities beyond one year are very illiquid. A second issue is that Black-Scholes assumes a lognormal density for the share value at maturity, where we have a potentially very different distribution as illustrated in Figure 3. There is also an issue that the lower boundary (where the manager gets fired) effectively turns the employee stock option into a knock-out call. In summary, estimating an implied volatility using the Black-Scholes model doesn't sound like an effective solution.

The most straight-forward approach is risk-neutral valuation using our model. Once we have the manager's optimal kappa choices at each grid point, we can calculate the risk-neutral density of the firm values at time $T$. We then calculate the risk-neutral expectation of the employee stock option payoff and discount it to the present at the riskless rate. This then 
provides an estimate of fair value which incorporates the manager's expected behavior as well as the knock-out characteristics of his option. In Table 7, we display such values for the same range of risk aversion parameters and wealth distribution as in Tables 3 and 6.

Table 7

\section{Fair Values for Differing Risk Aversion and Initial Wealth Structures with 1-Year Maturity Options}

We report the fair value of an employee stock option struck at-the-money for various levels of relative risk aversion (gamma) and initial wealth distributions $\left[\mathrm{b} /\left(\mathrm{a}^{\prime}+\mathrm{b}\right)\right]$. Other parameters are as specified in Table 1. The fair value is calculated as the discounted risk-neutral expectation of the terminal option payoff with managerial control. In the lower panel, we report the European certainty equivalent values divided by the fair value for that option.

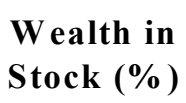

Stock $(\%)$

20
50
80

20

50

80

\section{Relative Risk Aversion

$0.5 \quad 2 \quad 4$

\section{Year European Options}

Fair Value

$\begin{array}{lll}0.1862 & 0.1779 & 0.1631\end{array}$

$0.1861 \quad 0.1693 \quad 0.1135$

$0.1860 \quad 0.1281 \quad 0.0941$

\section{CEV/Fair Value}

$\begin{array}{lll}1.20 & 0.89 & 0.68 \\ 1.13 & 0.74 & 0.57 \\ 1.07 & 0.67 & 0.45\end{array}$

In examining Table 7, recall that the Black-Scholes price for the comparable one-year option with a fixed volatility of $30 \%$ is 0.1282 . The upper panel of this table clearly indicates that it is possible to have a Fair value which is substantially greater or less than Black-Scholes price. The higher values are driven by lower risk aversion resulting in higher kappa values, with the largest effect coming from the Merton Flats area. There is also the knock-out characteristic of the employee stock option which reduces all of the fair values compared with Black-Scholes. For the manager with the lowest risk aversion, the higher average kappa more than overcomes the knockout adjustment, resulting in fair values substantially above Black-Scholes. 
The lower panel of Table 7 indicates that it is possible to have a subjective (CEV) option value which exceeds the fair value. This may seem surprising at first, but consider a simple example. Suppose the manager were personally risk neutral. He would discount the true expected payoff (generated with $\mu=0.092$ ) using the riskless rate of $2 \%$. Clearly, that value will exceed the similarly discounted risk-neutral expectation generated with a risk-neutral drift parameter of 0.02 .

\section{Concluding Comments}

The main message of this paper is that managerial control can dramatically affect the value of employee stock options. This is true both from the subjective (CEV) perspective of the manager and in terms of the option's fair value if its payoff pattern were priced in the market. The driving force here is the manager's ability to dramatically alter the distribution of potential firm values as illustrated in Figure 3.

Since the main rationale for using employee stock options is presumably to provide an incentive for improved performance, it is important to examine how that performance affects the option value. Here we take a relatively simple approach to modeling the manager's control ability, but one that seems reasonable for top management. Lower level employees would individually have less ability to alter firm-wide prospects. ${ }^{13}$ However, if their behaviors were highly correlated, the overall firm-wide effects could be similar to what we have modeled.

The comparative statics of our model are fairly straightforward. Increased risk aversion reduces the manager's subjective valuation of his incentive option. Having a larger fraction of his wealth tied up in the firm's stock has an analogous effect. Moreover, these two characteristics reinforce each other and can collectively reduce the manager's subjective valuation by a factor of 3 or more. When the incentive option is substantially in-the-money, the manager has less incentive to alter kappa. In the limit, he winds up in Merton Flats and pursues a constant-kappa strategy. Hence, his control ability plays less of a valuation role for in-the-money options. In that situation, fair value for his option will approach a Black-Scholes price using the volatility associated with the manager's optimal kappa from Merton Flats. Symmetrically,

13 An exception would be a lower level employee who controls large "hedge" positions. We know from situations such as the Baring's debacle that relatively low level employees can dramatically alter the riskiness of a major firm via large positions in financial contracts. 
managerial control plays a larger role in valuation for near-the-money and out-of-the-money options.

As illustrated in Tables 3 - 5, early exercise value depends on the manager's risk aversion, the degree to which his wealth is tied up in firm shares, and the moneyness of the option. Interestingly, it depends even more on his control ability. For comparably in-the-money options and equivalent other parameters, a manager with less control is more inclined to early exercise. This suggests that a typical lower level employee (with less control over the firm value process) is more inclined to early exercise than a top manager. This is an interesting and possibly testable implication of our model. The challenge will be to control for potentially differing risk aversion and wealth distributions - both of which are difficult to observe. ${ }^{14}$

Another potentially testable implication of our model is that share price volatility should decline (due to declining kappa) as the manager's incentive option position moves into-themoney. The challenges here will include estimating changing volatility as well as disentangling the effects of possibly multiple options with differing strikes and maturities. Furthermore, the volatility of volatility should increase as firms use more option compensation.

A related issue concerns how managerial control should influence the price of tradable derivatives. One can conceptually determine a pricing model for tradable derivatives conditional on knowing the manager's control behavior. The risk neutral pricing (fair value) we develop here for the manager's option is effectively a knock-out call that could be used to estimate an implied (average) volatility consistent with the manager's behavior.

There are also interesting issues regarding variations in the combination of incentives and controls in a dynamic framework such as ours. For example, the manager's risk taking on Option Ridge can be curtailed by limiting $\kappa$ or by altering the relative mix of shares and incentive options. If the manager has a minimum (reservation) expected utility level for accepting employment, then decreasing (for example) his incentive option position may need to be compensated via increasing either his restricted shares and/or fixed wages. How his compensation package is adjusted will influence the manager's risk taking not only on Option Ridge but in other portions of the state space. Moreover, his risk aversion and outside wealth will

14 Bettis, Bizjak, and Lemmon (2003) provide regression estimates that CEOs tend to exercise their options about four months later than other senior executives and six months later than nonmanagement directors. They view these results as due to differences in outside wealth and possibly risk aversion. Our model suggests an alternative explanation based on differing control abilities, with CEOs having the most control and non-management directors the least. 
play important roles, with differing managers having potentially very different responses to seemingly identical incentives. This opens up questions of how best to "manage the manager." We have not explored such issues here but intend to do so in the future.

\section{Appendix A: Numerical Procedure for Generating the Optimal Control Surface}

The basic structure of our model uses a grid of firm values $\mathrm{X}$ and time $\mathrm{t}$, with $\Delta(\log \mathrm{X})$ constant as well as time steps $\Delta \mathrm{t}$ of equal length. The initial firm value $\mathrm{X}_{0}$ is on the grid. To calculate expected utilities, we will need the probabilities of moving from one firm value at time $\mathrm{t}$ to all possible firm values that can be reached at $\mathrm{t}+\Delta \mathrm{t}$. The possible $\log \mathrm{X}$ moves are $i \Delta(\log X)$. We use $\mathrm{i}$ to index the grid points to which we can move. In the current implementation, the range for $\mathrm{i}$ is from $-20, \ldots, 0, \ldots, 20$. The probabilities for those possible moves depend on the choice of kappa which determines the process for $\mathrm{X}$ over the next time step. For a given kappa, the log change in $\mathrm{X}$ is normally distributed with mean $\mu_{\kappa, \Delta t}=\left[\kappa \mu+(1-\kappa) r-\frac{1}{2} \kappa^{2} \sigma^{2}\right] \Delta t \quad$ and volatility $\sigma_{\kappa, \Delta t}=\kappa \sigma \sqrt{\Delta t}$. Note that this mean and variance do not depend on the level of $\mathrm{X}$. They do depend on $\Delta \mathrm{t}$ but not on $\mathrm{t}$ itself. Since the normal distribution is characterized by its mean and variance, the probabilites we need are solely functions of $\kappa$ and not the grid point.

We now use the discrete normal distribution to generate the move probabilities. For a given kappa, we calculate the probabilities based on the normal density times a normalization constant so that the computed probabilities sum to one:

$$
p_{i, \kappa, \Delta t}=\frac{\frac{1}{\sqrt{2 \pi} \sigma} E X P\left[-\frac{1}{2}\left(\frac{i \Delta(\log X)-\mu_{\kappa, \Delta t}}{\sigma_{\kappa, \Delta t}}\right)^{2}\right]}{\sum_{j=-20}^{20} \frac{1}{\sqrt{2 \pi} \sigma} E X P\left[-\frac{1}{2}\left(\frac{j \Delta(\log X)-\mu_{\kappa, \Delta t}}{\sigma_{\kappa, \Delta t}}\right)^{2}\right]}
$$

We keep a lookup table of the probabilities for different choices of kappa, which we vary in our standard case from 0.7 to 1.5 in steps of 0.1 . Particularly when using wider bounds on kappa, the ends of this range are problematic and can result in poor approximations to the normal 
distribution. For low kappa values, the approximation suffers from not having fine enough value steps. For high kappa values, the difficulty arises from potentially not having enough offset range to accommodate the extreme tails of the distribution.

To insure reasonable accuracy, we compare the standardized moments of our approximated normal distribution $\hat{\mu}_{j}$ with the theoretical moments of the standard normal, $\mu_{j}=1 \cdot 3 \cdot \ldots \cdot(j-1)$ for $\mathrm{j}$ even and $\mu_{j}=0$ for $\mathrm{j}$ odd. In particular, we calculate a test statistic based on the differences of the first 10 approximated and theoretical moments scaled by the asymptotic variance of the moment estimation - see Stuart and Ord (1987, p. 322):

$$
\frac{1}{10} \sum_{j=1}^{10}\left(\frac{\hat{\mu}_{j}-\mu_{j}}{\frac{1}{n}\left(\mu_{2 j}-\mu_{j}^{2}+j^{2} \mu_{2} \mu_{j-1}^{2}-2 j \mu_{j-1} \mu_{j+1}\right)}\right)^{2}, \text { where we set } n=1
$$

After some experimentation, we discard distributions with a test statistic of more than 0.01. For the model parameters in Table 1, we do not need to eliminate any kappa levels due to this approximation issue. This process results in a matrix of probabilities with a probability vector for each kappa value in our choice set.

We now calculate the expected indirect utilities after initializing the terminal indirect utilities $\mathrm{J}_{\mathrm{T}}$ to the utility of wealth of our manager $\mathrm{U}_{\mathrm{X}, \mathrm{T}}\left(\mathrm{W}_{\mathrm{T}}\right)$, where his wealth $\mathrm{W}_{\mathrm{T}}$ is determined by $\mathrm{X}_{\mathrm{T}}$ and his compensation scheme. Our next task is to calculate the indirect utility function at earlier time steps as an expectation of future indirect utility levels. We commence stepping backwards in time from the terminal date $\mathrm{T}$ in steps of $\Delta \mathrm{t}$. At each firm value within a time step $t$, we calculate the expected indirect utilities for all kappa levels using the stored probabilities and record the highest value as our optimal indirect utility, $\mathrm{J}_{\mathrm{X}, \mathrm{t}}$. We continue, looping backward in time through all time steps.

In our situation, using a lookup table for the probabilities associated with the kappas has two advantages compared with using an optimization routine to find the optimal kappa. For one, lookups are faster although coarser than optimizations. Second, a sufficiently fine lookup table is a global optimization method that will find the true maximum even for non-concave indirect utility functions. In such situations, a local optimization routine can get stuck at a local maximum and gradient-based methods might face difficulties due to discontinuous derivatives. 
When implementing our backward sweep through the grid, we have to deal with behavior at the boundaries. The terminal step is trivial in that we calculate the terminal utility from the terminal wealth. The lower boundary is also quite straightforward. We stop the process upon reaching or crossing the boundary and calculate the utility associated with hitting the boundary at that time $(\tau)$. In that situation, the manager's terminal wealth has the known value of $W_{T}=a+b X_{\tau}$ for which we can calculate the utility. We use this lower boundary value in calculating the expected indirect utility at earlier time steps.

For the numerical implementation, we also need an upper boundary to approximate indirect utilities associated with high firm values. We use a boundary 40 steps above the initial $\mathrm{X}_{0}$ level. For firm values near that boundary, our calculation of the expected indirect utility will try to use indirect utilities associated with firm values above the boundary. We deal with this by keeping a buffer of firm values above the boundary so that the expected indirect utility can be calculated by looking up values from such points. We set the terminal buffer values simply to the utility for the wealth level associated with those firm values. We then step back in time and use as our indirect utility the utility of the following date times a multiplier which is based on the optimal Merton (1969) solution without consumption and outside wealth: $\exp \left[\Delta t(\mu-r)^{2}(1-\gamma) /\left(2 \gamma \sigma^{2}\right)\right]$. We do not assume that these values are correct (they are based on a continuous time model while we work in a discrete time setting) but they work very well. This approach is potentially suboptimal, which biases the results low. However, the distortion ripples only a few steps below the upper boundary, affecting mainly the early time steps. 


\section{Appendix B: Numerical Procedure with Possible Early Exercise}

With early exercise, there is path dependence in the problem since the optimal decision after an early exercise will depend on how much the manager gained (in stock or cash) in the early exercise. That will in turn affect the kappa surface. The way we proceed is to construct a surface of optimal indirect utilities, conditional on having exercised at that particular grid point. This surface is based on an adjusted payoff function. When the manager exercises for shares, his

share position becomes $b+\frac{c\left(X_{\tau}-X_{0}\right)}{X_{\tau}}$. We alternatively consider his exercising for cash with those proceeds held until $\mathrm{T}$ without any interest payment. This results in an adjusted outside wealth position of $a+c\left(X_{\tau}-X_{0}\right)$.

Note that these adjusted values depend on the firm value $X_{\tau}$ where exercise occurs but do not depend on the exercise time $\tau$. This feature allows us to keep the problem computationally manageable. Namely, we can construct an optimal indirect utility surface (for all states and time steps) conditional on having exercised at the firm value $\mathrm{X}_{\tau}$. For example, when exercising for shares, we adjust the manager's share position and sweep backward through the $(\mathrm{X}, \mathrm{t})$ grid, calculating the optimal kappa and indirect utility at each node. This results in a surface of indirect utilities and kappas which is optimal for that $X_{\tau}$ value. We repeat this procedure for each $\mathrm{X}$ value greater than the strike price. From each of those surfaces, we use the row of $\mathrm{X}$ values which has $\mathrm{X}=\mathrm{X}_{\tau}$, to build a composite surface of indirect utility values conditional on having exercised (at some $\mathrm{X}_{\tau}$ ).

Then, we work out the optimal final indirect utility surface, determining at each node whether or not it is preferable to exercise. We start at time $\mathrm{T}$ with a live option and work backward. We compare the indirect utility of continuing with a live option to the indirect utility of early exercise (from our composite surface). If early exercise is preferred, we insert that indirect utility at the relevant node and continue looping backwards to the beginning of the grid. 


\section{References}

Carpenter, Jennifer N. (1998). "The Exercise and Valuation of Executive Stock Options." Journal of Financial Economics 48, 127-158.

Bettis, J. Carr, Bizjak, John M., and Michael L. Lemmon (2003). "Exercise Behavior and the Valuation and Incentives of Employee Stock Options." working paper, Arizona State University, August.

Detemple, Jerome, and Suresh Sundaresan (1999). "Nontraded Asset Valuation with Portfolio Constraints: A Binomial Approach.” Review of Financial Studies 12, No. 4, 835-872.

FASB (2004), "Statement of Financial Accounting Standards No. 123 (revised 2004): ShareBased Payment." http://www.fasb.org/pdf/fas123r.pdf

Hall, Brian J., and Kevin J. Murphy (2002). "Stock Options for Undiversified Executives." Journal of Accounting and Economics 33, 3-42.

Hodder, James E and Jens C. Jackwerth (2004). "Incentive Contracts and Hedge Fund Management.” Working paper, University of Konstanz, May.

Huddart, Steven (1994). "Employee Stock Options." Journal of Accounting and Economics 18, 207-231.

Ingersoll, Jonathan E. (2004). "The Subjective and Objective Evaluation of Incentive Stock Options." Journal of Business, forthcoming.

Judd, Kenneth L. (1998). Numerical Methods in Economics, MIT Press, Cambridge, MA.

Kulatilaka, Nalin, and Alan J. Marcus (1994). "Valuing Employee Stock Options." Financial Analyst Journal 50, No. 6, 46-56.

Lambert, Richard A., David F. Larcker, and Robert E. Verrecchia (1991). "Portfolio Considerations in Valuing Executive Compensation." Journal of Accounting Research 29, No. 1, 129-149.

Lewellen, Katharina (2003). "Financing Decisions when Managers are Risk Averse." Working Paper, MIT, August.

Merton, Robert (1969), "Lifetime Portfolio Selection under Uncertainty: The Continuous Time Case," Review of Economics and Statistics 51, 247-257.

Rubinstein, Mark (1976), "The Valuation of Uncertain Income Streams and the Pricing of Options," Bell Journal of Economics 7, 407-425.

Stuart, A., and S. Ord (1987), Kendall's Advanced Theory of Statistics, Vol. 1, $5^{\text {th }}$ ed. Oxford University Press, New York. 


\section{List of other working papers:}

\section{5}

1. Shaun Bond and Soosung Hwang, Smoothing, Nonsynchronous Appraisal and CrossSectional Aggreagation in Real Estate Price Indices, WP05-17

2. Mark Salmon, Gordon Gemmill and Soosung Hwang, Performance Measurement with Loss Aversion, WP05-16

3. Philippe Curty and Matteo Marsili, Phase coexistence in a forecasting game, WP05-15

4. Matthew Hurd, Mark Salmon and Christoph Schleicher, Using Copulas to Construct Bivariate Foreign Exchange Distributions with an Application to the Sterling Exchange Rate Index (Revised), WP05-14

5. Lucio Sarno, Daniel Thornton and Giorgio Valente, The Empirical Failure of the Expectations Hypothesis of the Term Structure of Bond Yields, WP05-13

6. Lucio Sarno, Ashoka Mody and Mark Taylor, A Cross-Country Financial Accelorator: Evidence from North America and Europe, WP05-12

7. Lucio Sarno, Towards a Solution to the Puzzles in Exchange Rate Economics: Where Do We Stand?, WP05-11

8. James Hodder and Jens Carsten Jackwerth, Incentive Contracts and Hedge Fund Management, WP05-10

9. James Hodder and Jens Carsten Jackwerth, Employee Stock Options: Much More Valuable Than You Thought, WP05-09

10. Gordon Gemmill, Soosung Hwang and Mark Salmon, Performance Measurement with Loss Aversion, WP05-08

11. George Constantinides, Jens Carsten Jackwerth and Stylianos Perrakis, Mispricing of S\&P 500 Index Options, WP05-07

12. Elisa Luciano and Wim Schoutens, A Multivariate Jump-Driven Financial Asset Model, WP0506

13. Cees Diks and Florian Wagener, Equivalence and bifurcations of finite order stochastic processes, WP05-05

14. Devraj Basu and Alexander Stremme, CAY Revisited: Can Optimal Scaling Resurrect the (C)CAPM?, WP05-04

15. Ginwestra Bianconi and Matteo Marsili, Emergence of large cliques in random scale-free networks, WP05-03

16. Simone Alfarano, Thomas Lux and Friedrich Wagner, Time-Variation of Higher Moments in a Financial Market with Heterogeneous Agents: An Analytical Approach, WP05-02

17. Abhay Abhayankar, Devraj Basu and Alexander Stremme, Portfolio Efficiency and Discount Factor Bounds with Conditioning Information: A Unified Approach, WP05-01

\section{4}

1. Xiaohong Chen, Yanqin Fan and Andrew Patton, Simple Tests for Models of Dependence Between Multiple Financial Time Series, with Applications to U.S. Equity Returns and Exchange Rates, WP04-19

2. Valentina Corradi and Walter Distaso, Testing for One-Factor Models versus Stochastic Volatility Models, WP04-18

3. Valentina Corradi and Walter Distaso, Estimating and Testing Sochastic Volatility Models using Realized Measures, WP04-17

4. Valentina Corradi and Norman Swanson, Predictive Density Accuracy Tests, WP04-16

5. Roel Oomen, Properties of Bias Corrected Realized Variance Under Alternative Sampling Schemes, WP04-15

6. Roel Oomen, Properties of Realized Variance for a Pure Jump Process: Calendar Time Sampling versus Business Time Sampling, WP04-14 
7. Richard Clarida, Lucio Sarno, Mark Taylor and Giorgio Valente, The Role of Asymmetries and Regime Shifts in the Term Structure of Interest Rates, WP04-13

8. Lucio Sarno, Daniel Thornton and Giorgio Valente, Federal Funds Rate Prediction, WP04-12

9. Lucio Sarno and Giorgio Valente, Modeling and Forecasting Stock Returns: Exploiting the Futures Market, Regime Shifts and International Spillovers, WP04-11

10. Lucio Sarno and Giorgio Valente, Empirical Exchange Rate Models and Currency Risk: Some Evidence from Density Forecasts, WP04-10

11. Ilias Tsiakas, Periodic Stochastic Volatility and Fat Tails, WP04-09

12. Ilias Tsiakas, Is Seasonal Heteroscedasticity Real? An International Perspective, WP04-08

13. Damin Challet, Andrea De Martino, Matteo Marsili and Isaac Castillo, Minority games with finite score memory, WP04-07

14. Basel Awartani, Valentina Corradi and Walter Distaso, Testing and Modelling Market Microstructure Effects with an Application to the Dow Jones Industrial Average, WP04-06

15. Andrew Patton and Allan Timmermann, Properties of Optimal Forecasts under Asymmetric Loss and Nonlinearity, WP04-05

16. Andrew Patton, Modelling Asymmetric Exchange Rate Dependence, WP04-04

17. Alessio Sancetta, Decoupling and Convergence to Independence with Applications to Functional Limit Theorems, WP04-03

18. Alessio Sancetta, Copula Based Monte Carlo Integration in Financial Problems, WP04-02

19. Abhay Abhayankar, Lucio Sarno and Giorgio Valente, Exchange Rates and Fundamentals: Evidence on the Economic Value of Predictability, WP04-01

\section{2}

1. Paolo Zaffaroni, Gaussian inference on Certain Long-Range Dependent Volatility Models, WP02-12

2. Paolo Zaffaroni, Aggregation and Memory of Models of Changing Volatility, WP02-11

3. Jerry Coakley, Ana-Maria Fuertes and Andrew Wood, Reinterpreting the Real Exchange Rate - Yield Diffential Nexus, WP02-10

4. Gordon Gemmill and Dylan Thomas, Noise Training, Costly Arbitrage and Asset Prices: evidence from closed-end funds, WP02-09

5. Gordon Gemmill, Testing Merton's Model for Credit Spreads on Zero-Coupon Bonds, WP0208

6. George Christodoulakis and Steve Satchell, On th Evolution of Global Style Factors in the MSCI Universe of Assets, WP02-07

7. George Christodoulakis, Sharp Style Analysis in the MSCI Sector Portfolios: A Monte Caro Integration Approach, WP02-06

8. George Christodoulakis, Generating Composite Volatility Forecasts with Random Factor Betas, WP02-05

9. Claudia Riveiro and Nick Webber, Valuing Path Dependent Options in the Variance-Gamma Model by Monte Carlo with a Gamma Bridge, WP02-04

10. Christian Pedersen and Soosung Hwang, On Empirical Risk Measurement with Asymmetric Returns Data, WP02-03

11. Roy Batchelor and Ismail Orgakcioglu, Event-related GARCH: the impact of stock dividends in Turkey, WP02-02

12. George Albanis and Roy Batchelor, Combining Heterogeneous Classifiers for Stock Selection, WP02-01

\section{1}

1. Soosung Hwang and Steve Satchell, GARCH Model with Cross-sectional Volatility; GARCHX Models, WP01-16

2. Soosung Hwang and Steve Satchell, Tracking Error: Ex-Ante versus Ex-Post Measures, WP01-15

3. Soosung Hwang and Steve Satchell, The Asset Allocation Decision in a Loss Aversion World, WP01-14

4. Soosung Hwang and Mark Salmon, An Analysis of Performance Measures Using Copulae, WP01-13

5. Soosung Hwang and Mark Salmon, A New Measure of Herding and Empirical Evidence, WP01-12 
6. Richard Lewin and Steve Satchell, The Derivation of New Model of Equity Duration, WP0111

7. Massimiliano Marcellino and Mark Salmon, Robust Decision Theory and the Lucas Critique, WP01-10

8. Jerry Coakley, Ana-Maria Fuertes and Maria-Teresa Perez, Numerical Issues in Threshold Autoregressive Modelling of Time Series, WP01-09

9. Jerry Coakley, Ana-Maria Fuertes and Ron Smith, Small Sample Properties of Panel Timeseries Estimators with I(1) Errors, WP01-08

10. Jerry Coakley and Ana-Maria Fuertes, The Felsdtein-Horioka Puzzle is Not as Bad as You Think, WP01-07

11. Jerry Coakley and Ana-Maria Fuertes, Rethinking the Forward Premium Puzzle in a Nonlinear Framework, WP01-06

12. George Christodoulakis, Co-Volatility and Correlation Clustering: A Multivariate Correlated ARCH Framework, WP01-05

13. Frank Critchley, Paul Marriott and Mark Salmon, On Preferred Point Geometry in Statistics, WP01-04

14. Eric Bouyé and Nicolas Gaussel and Mark Salmon, Investigating Dynamic Dependence Using Copulae, WP01-03

15. Eric Bouyé, Multivariate Extremes at Work for Portfolio Risk Measurement, WP01-02

16. Erick Bouyé, Vado Durrleman, Ashkan Nikeghbali, Gael Riboulet and Thierry Roncalli, Copulas: an Open Field for Risk Management, WP01-01

\section{0}

1. Soosung Hwang and Steve Satchell, Valuing Information Using Utility Functions, WP00-06

2. Soosung Hwang, Properties of Cross-sectional Volatility, WP00-05

3. Soosung Hwang and Steve Satchell, Calculating the Miss-specification in Beta from Using a Proxy for the Market Portfolio, WP00-04

4. Laun Middleton and Stephen Satchell, Deriving the APT when the Number of Factors is Unknown, WP00-03

5. George A. Christodoulakis and Steve Satchell, Evolving Systems of Financial Returns: AutoRegressive Conditional Beta, WP00-02

6. Christian S. Pedersen and Stephen Satchell, Evaluating the Performance of Nearest Neighbour Algorithms when Forecasting US Industry Returns, WP00-01

\section{9}

1. Yin-Wong Cheung, Menzie Chinn and Ian Marsh, How do UK-Based Foreign Exchange Dealers Think Their Market Operates?, WP99-21

2. Soosung Hwang, John Knight and Stephen Satchell, Forecasting Volatility using LINEX Loss Functions, WP99-20

3. Soosung Hwang and Steve Satchell, Improved Testing for the Efficiency of Asset Pricing Theories in Linear Factor Models, WP99-19

4. Soosung Hwang and Stephen Satchell, The Disappearance of Style in the US Equity Market, WP99-18

5. Soosung Hwang and Stephen Satchell, Modelling Emerging Market Risk Premia Using Higher Moments, WP99-17

6. Soosung Hwang and Stephen Satchell, Market Risk and the Concept of Fundamental Volatility: Measuring Volatility Across Asset and Derivative Markets and Testing for the Impact of Derivatives Markets on Financial Markets, WP99-16

7. Soosung Hwang, The Effects of Systematic Sampling and Temporal Aggregation on Discrete Time Long Memory Processes and their Finite Sample Properties, WP99-15

8. Ronald MacDonald and Ian Marsh, Currency Spillovers and Tri-Polarity: a Simultaneous Model of the US Dollar, German Mark and Japanese Yen, WP99-14

9. Robert Hillman, Forecasting Inflation with a Non-linear Output Gap Model, WP99-13

10. Robert Hillman and Mark Salmon, From Market Micro-structure to Macro Fundamentals: is there Predictability in the Dollar-Deutsche Mark Exchange Rate?, WP99-12

11. Renzo Avesani, Giampiero Gallo and Mark Salmon, On the Evolution of Credibility and Flexible Exchange Rate Target Zones, WP99-11

12. Paul Marriott and Mark Salmon, An Introduction to Differential Geometry in Econometrics, WP99-10 
13. Mark Dixon, Anthony Ledford and Paul Marriott, Finite Sample Inference for Extreme Value Distributions, WP99-09

14. Ian Marsh and David Power, A Panel-Based Investigation into the Relationship Between Stock Prices and Dividends, WP99-08

15. Ian Marsh, An Analysis of the Performance of European Foreign Exchange Forecasters, WP99-07

16. Frank Critchley, Paul Marriott and Mark Salmon, An Elementary Account of Amari's Expected Geometry, WP99-06

17. Demos Tambakis and Anne-Sophie Van Royen, Bootstrap Predictability of Daily Exchange Rates in ARMA Models, WP99-05

18. Christopher Neely and Paul Weller, Technical Analysis and Central Bank Intervention, WP9904

19. Christopher Neely and Paul Weller, Predictability in International Asset Returns: A Reexamination, WP99-03

20. Christopher Neely and Paul Weller, Intraday Technical Trading in the Foreign Exchange Market, WP99-02

21. Anthony Hall, Soosung Hwang and Stephen Satchell, Using Bayesian Variable Selection Methods to Choose Style Factors in Global Stock Return Models, WP99-01

1998

1. Soosung Hwang and Stephen Satchell, Implied Volatility Forecasting: A Compaison of Different Procedures Including Fractionally Integrated Models with Applications to UK Equity Options, WP98-05

2. Roy Batchelor and David Peel, Rationality Testing under Asymmetric Loss, WP98-04

3. Roy Batchelor, Forecasting T-Bill Yields: Accuracy versus Profitability, WP98-03

4. Adam Kurpiel and Thierry Roncalli, Option Hedging with Stochastic Volatility, WP98-02

5. Adam Kurpiel and Thierry Roncalli, Hopscotch Methods for Two State Financial Models, WP98-01 